\title{
Recombinant Fibroblast Growth Factor
}

National Cancer Institute

\section{Source}

National Cancer Institute. Recombinant Fibroblast Growth Factor. NCI Thesaurus. Code C496.

A recombinantly produced fibroblast growth factor family protein, with potential therapeutic applications. 